\title{
Digital Fundraising Model of Cash Waqf
}

\author{
Rahmatullah ${ }^{1}$, Bintang Ramadhan Putra ${ }^{2}$ \\ ${ }^{1,2}$ Fakultas Ekonomi dan Bisnis, Universitas Airlangga \\ *Email Korespondensi: rahmatullah-2018@pasca.unair.ac.id
}

Waqaf has an important position in Islam, namely as a form of worship that requires the abuse of a Muslim to provide his part to the interests of worship and kindness. There have been many models of fundraise that have been implemented by various waqaf institutions, among us the raising methods through membership, using volunteers and utilizing corporate funds. But in the digital era, there is a need to study the digital fundraising model. This paper aims to offer solutions for Waqaf Institutions who want to make the watershed funds in digital but with several stages to note. The method used in this research is descriptive analysis with referring to the source of reading. The results of this study, researchers offer stages to note in directional duration of data: Digital Analysis, Digital Vision, Digital Message, Digital Channel, Digital Campaign, and Digital Report. It is expected that this can contribute in the process of waqaf funding.

Keywords: Digital Fundraising Model, Cash, Waqf

Saran sitasi: Rahmatullah., \& Putra, B. R. (2020). Digital Fundraising Model of Cash Waqf. Jurnal Ilmiah Ekonomi Islam, 6(03), 553-556. doi: http://dx.doi.org/10.29040/jiei.v6i3.1382

DOI: http://dx.doi.org/10.29040/jiei.v6i3.1382

\section{PENDAHULUAN}

Konsep fundraising perlu dikenali secara komprehensif pada lembaga wakaf guna mendorong perkembangannya. Fundraising terkadang dipahami sebagai hal yang sama dengan organisasi nirlaba (Worth, 2017), menurut Worth fundraising adalah suatu gerakan yang dimulai dengan tujuan beramal atau bederma. Sederhananya, fundraising memiliki arti "meminta hadiah" meskipun prosesnya panjang dan lebih rumit.

Penghimpunan atau fundraising dalam istilah merupakan suatu upaya atau proses kegiatan dalam rangka menghimpun dana (wakaf) serta sumber daya lainnya dari masyarkat baik individu, kelompok, organisasi yang akan disalurkan dan didayagunakan (Depag RI, 2009). Penghimpunan ini juga bagian dari proses syiar bagi masyarakat atau disebut calon wakif agar mau ikut dalam melakukan aktivitas wakaf. Adapun model-model fundraising wakaf ini harus memperhatikan subtansi dari fundraising tersebut, seperti motivasi, program, dan metode. (Huda, 2013)

Metode dalam bagian subtansi fundraising merupakan hal yang khas dilakukan oleh nazir dalam rangka menghimpun dana masyarkat, yang mana metode ini terbagi atas dua jenis, diantaranya langsung (direct) dan tidak langsung (indirect). Adapun yang dimaksud lansung (direct) adalah metode yang menggunakan teknik-teknik atau cara-cara yang melibatkan partisipasi waqif secara langsung, yaitu bentuk-bentuk fundraising dimana proses interaksi dan daya akomodasi terhadap respons waqif bisa seketika (langsung) dilakukan. Sebagai contoh dari metode ini adalah: direct mail, direct advertising, dan presentasi langsung. Sedangkan fundraising tidak langsung (indirect fundraising), yaitu suatu metode yang menggunakan teknik-teknik atau cara-cara yang tidak melibatkan partisipasi waqif secara langsung. yaitu bentuk-bentuk fundraising di mana tidak dilakukan dengan memberikan daya akomodasi langsung terhadap respon waqif seketika. Sebagai contoh dari metode ini adalah: advertorial, image compaign, dan penyelenggaraan event, melalui perantara, menjalin relasi, melalui referensi, dan mediasi para tokoh, dan lainnya (Saidi, 2005).

Wakaf memiliki kedudukan penting dalam Islam, yakni sebagai bentuk ibadah yang mengharuskan kerelaan dari seorang muslim untuk memberikan sebagian miliknya kepada kepentingan ibadah dan 


\section{Jurnal Ilmiah Ekonomi Islam, 6(03), 2020, 554}

kebaikan. Sebagaimana Allah berfirman dalam Alquran "kamu sekali-sekali tidak sampai kepada kebaikan (yang sempurna), sebelum kamu menafkahkan sebagian harta yang kamu cintai. Maka sesungguhnya Allah mengetahui apa saja yang kamu nafkahkan”. (QS. Ali Imron (3): 92).

Wakaf sendiri secara etimologi berarti "menahan, mencegah, selama, tetap, paham, menghubungkan, mencabut, meninggalkan, dan lain sebagainya" (Ma'luf dalam haq: 2013: 1). Sedangkan kata wakaf sendiri menurut Kamus Besar Bahasa Indonesia (Tim Prima Pena, 2002: 795) bermakna: "pemberian yang ikhlas dari seseorang berupa benda bergerak atau tidak bergerak bagi kepentingan umum yang dibentuk yang berkaitan dengan agama Islam.” Menurut (Qahar, 2005) wakaf produktif adalah harta benda atau pokok tetap yang diwakafkan untuk dipergunakan dalam kegiatan produksi dan hasilnya disalurkan sesuai dengan tujuan wakaf, seperti tanah untuk dipergunakan bercocok tanam, mata air untuk dijual airnya dan lain-lain.

Sedangkan menurut Uha (Bank Indonesia, 2016: 42) membagi wakaf dalam substansi ekonomi yakni terdiri: Pertama Wakaf langsung yaitu wakaf untuk memberikan pelayanan langsung kepada orang-orang yang berhak, seperti masjid, sekolah, dan rumah sakit. Kedua, Wakaf Produktif yaitu harta yang dikembangkan sehingga menghasilkan keuntungan bersih yang nantinya akan diberikan kepada orangorang yang berhak sesuai tujuan wakaf, seperti kegiatan social dan peribadatan. Ketiga, Wakaf tunai atau uang, yakni berupa uang yang diwakafkan untuk menjadi dana pinjaman bergulir tanpa bunga bagi pihak-pihak yang membutuhkan dan menjadi modal bagi usaha-usaha produktif.

\section{KAJIAN TEORI}

Salah satu masalah utama dalam pengelolaan wakaf adalah bagaimana menjaga ketersediaan dana wakaf, sehingga dapat mempertahankan nilai aslinya dan mengembangkannya dari waktu ke waktu (Arshad \& Hanef, 2016).

Penelitian yang dilakukan oleh (Ubed, 2014) telah mengkaji metode-metode dalam fundraising wakaf uang, yang mana dalam penelitiannya ia menyarankan kepada Badan Wakaf Indonesia dalam metode fundraising wakaf uang, yakni dengan metode penggalangan melalui membership, penawaran partisipasi melalui direct mail, menggunakan relawan dan memanfaatkan dana perusahaan, disamping itu juga ia menyarakan agar Badan Wakaf Indonesia memiliki bidang fundraising sendiri yang khusus bertugas dalam pengumpulan dana wakaf uang. Ditahun berikutnya (Faradis, dkk, 2015) meneliti tentang Perbedanan Wakaf Selangor Malaysia dan Badan Wakaf Indonesia. Tujuan dari penelitian ini adalah untuk menganalisis kondisi BWI dan PWS dalam penghimpunan wakaf produktif. Hasilnya adalah, masing-masing dari lembaga ini memiliki dua metode yakni: metode pertama diawali dengan membuka rekening di lembaga keuangan syariah penerima wakaf uang atas nama BWI. Sedangkan PWS mengawali dengan membuka Counter PWS, membuka rekening di Lembaga Keuangan Syariah Penerima Wakaf atas nama PWS, skim infaq potong gaji) dan Portal e-mail, serta bekerja sama dengan Lembaga pendidikan. Metode kedua yaitu adanya interaksi langsung antara BWI dengan calon Wakif dengan cara mendatangi langsung ke instansi baik negeri maupun swasta. Sedangkan PWS menggunakan tiga model yakni: Bulan Wanita dan Wakaf, bulan wakaf Selangor dan ketiga bulan Masre Industri, dalam kesimpulannya bahwa diantara dua lembaga ini masing-masing menggunakan dua metode yakni "menunggu bola" dan "jemput bola".

Suhaili \& Palil (2017) dalam penelitiannya mencoba untuk menangkap pemahaman operasionalisasi kolaborasi menggunakan platform penggalangan dana berbasis teknologi pada umumnya. Hasilnya adalah crowdfunding berbasis teknologi memiliki nilai keunggulan untuk entitas wakaf dalam mengeksplorasi landskap yang disediakan dalam crowdfounding. Kemudian, penelitian yang dibuat oleh (Shulthoni \& Saad, 2018) mengungkapkan harus adanya pembaruan dalam sistem fundraising yang ditelitinya atas dasar perbandingan institusi wakaf tradisional dan modern. Tidak kalah modern dengan penelitian yang dilakukan oleh (Thaker, Thaker, \& Pitchay, 2018), mereka menawarkan model sumber pembiyaan yang berkelanjutan pada lembaga wakaf untuk memenuhi kendala likuiditas mereka dalam mengembangkan tanah wakaf yang dikenal sebagai model crowdfunding. Kemudian, CWM memvalidasi penerimaannya dilapangan diantara para crowdfounder dengan mengadopsi teori model penerimaan teknologi.

Saat sekarang, berbagai macam platform yang hadir dalam proses penghimpunan dana wakaf, ada platform yang sukses menjalankan misi 
penghimpunannya, ada platform yang masih jauh dari target apa yang diharapakan. Maka dari itu penulis memberikan ide-ide awal dalam proses Digital Fundraising Model of Cash Waqf yang mana nantinya dapat bermanfaat untuk dikembangkan oleh bidang fundraising disetiap lembaga wakaf.

\section{METODOLOGI PENELITIAN}

Penelitian ini adalah penelitian kualitatif yang bersifat studi pustaka (library research) yang menggunakan buku-buku dan literature mendukung lainnya sebagai objek utama (Hadi, 1995). Dengan penelitian kualitatif, perlu dilakukan analisis deskriptif. Pendekatan kualitatif yang didasarkan pada langkah awal yang ditempuh dengan mengumpulkan data-data yang dibutuhkan, kemudian dilakukan klasifikasi dan deskripsi.

\section{HASIL DAN PEMBAHASAN}

Berdasarkan hasil kajian literatur diatas, banyak sudah yang menawarkan berbagai macam model ataupun metode dalam proses penghimpunan dana wakaf tunai, namun disini penulis ingin menyampaikan hal-hal yang dianggap dasar dalam proses Digital fundraising ini agar dapat mengoptimalkan hasil yang diaharapkan oleh lembaga wakaf. Diantaranya sebagai berikut:

\section{Digital Analysis}

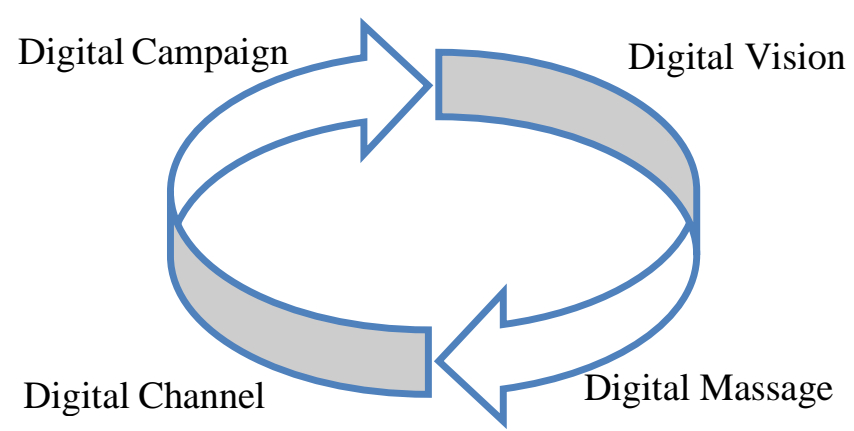

Digital Report

Sumber: Ilustrasi Oleh Penulis (2020)

\section{Langkah 1. Digital Analysis}

Dalam hal ini, lembaga wakaf yang dikelola oleh nazir harus mengetahui apa kelemahan dan kekuatan yang dimiliki dalam penggalangan dana secara digital. Perlu sekiranya mengetahui peluang yang dapat diciptakan apabila dana tersebut terkumpul.

\section{Langkah 2. Digital Vision}

Ini adalah proses dimana nazhir dapat mendefinisikan secara jelas mengapa lembaga wakaf yang dikelola oleh nazir tersebut relevan untuk menerima dana wakaf, branding dan positioning sangat diperlukan agar wakif dapat dengan mudah terpengaruh untuk memberikan sebagian hartanya untuk di wakafkan.

\section{Langkah 3. Digital Message}

Pada bagian ini, Nazir diusahakan untuk menjadi kreatif dalam membuat konten-konten yang akan disampaikan kepublik. Dengan baiknya konten yang diberikan akan menambahkan kepercayaan kepada calon wakif untuk menyumbangkan hartanya.

\section{Langkah 4. Digital Channel}

Dengan analisis yang baik, serta visi dan pesan yang akan disampaikan juga baik, maka langkah selanjutnya yang perlu dilakukan adalah membuat Saluran Digital. Dalam hal ini kita bisa menggunakan platform social media untuk membuat campaign, dan juga website yang saat ini telah banyak hadir yang berbasis crowdfunding.

\section{Langkah 5. Digital Campaign}

Dilangkah ke lima ini, kita akan dikenakan biaya harian, bulanan dan tahunan. Dalam melakukan campaign digital ini tentu tidak sembarangan, langkah 1, 2, 3, dan 4 perlu diperhatikan dengan baik agar calon wakif tepat sasaran atau sesuai target.

\section{Langkah 6. Digital Report}

Setelah masa iklan selesai, maka akan ada muncul dalam laporan periklanan, dari laporan tersebut kita dapat mengoreksi hasil media campaign yang telah kita buat

\section{KESIMPULAN}

Lembaga wakaf dalam hal ini terkait fundraising telah banyak mengalami berbagai macam model dalam proses penghimpunannya, diantaranya penggalangan melalui membership, penawaran partisipasi melalui direct mail, menggunakan relawan dan memanfaatkan dana perusahaan, hal ini bertujuan tidak lain untuk menjaga ketersediaan dana wakaf pada suatu lembaga wakaf tersebut. Adapun dalam perkembangan yang serba digital ini, perlu ada sedikit saran dari penulis dalam proses penghimpunan dana wakaf ini, mengingat begitu banyak platform digital yang hadir dalam proses penghimpun dana wakaf ini. Guna tercapainya target penghimpunan dana, penulis telah memberikan masukan dalam proses awal digital fundraising ini, yakni: Digital Analysis, Digital Vision, Digital Message, Digital Channel, Digital Campaign, dan Digital Report.

Diharapkan dengan mengetahui langkah awal dalam penghimpunan dana secara digital ini, dapat 


\section{Jurnal Ilmiah Ekonomi Islam, 6(03), 2020, 556}

memaksimalkan pendapatan yang diterima oleh masing-masing lembaga wakaf khususnya divisi fundraising.

\section{DAFTAR PUSTAKA}

Ahmed, H. (2007). Waqf -Based Microfinance: Realizing The Social Role of Islamic Finance "Integrating Awqaf in the Islamic Financial Sector". Integrating Awqaf in the Islamic Financial Sector, 1-22.

Arshad, M., \& Hanef, M. (2016). Third sector SocioEconomic models: How waqf fits in? International Journal of Institutions and Economies, 75-93.

Bank Indonesia, U. (2016). Wakaf: Pengaturan dan Tata Kelola yang Efektif. Jakarta: DEKS - Bank Indonesia.

Faradis, J., Khilmi, S., \& Affandi, M. Y. (2015). Manajemen Fundraising Wakaf Produktif: Perbandingan Wakaf Selangor (PWS) Malaysia dan Badan Wakaf Indonesia. Jurnal Ilmu Syariah dan Hukum, 500-518.

Hadi, S. (1995). Metodologi Research Jilid 3. Yogyakarta.

Huda, M. (2013). Model Manajemen Fundraising Wakaf. AHKAM: Jurnal Ilmu Syariah.

Qahar, M. (2005). Manajemen Wakaf Produktif. Jakarta: PT. Khalifa.
Saidi, Z. (2005). Kewiraswastaan Sosial Strategi Pengembangan Bisnis Berwawasan Sosial Bagi Lembaga Swadaya Masyarakat (LSM). Jakarta: Piramedia.

Shulthoni, M., \& Saad, N. M. (2018). Waqf Fundraising Management: A Conceptual Comparison Between Traditional and Modern Methods In the Waqf Institutions. Indonesian Journal of Islam and Muslim Societies, 57-86.

Suhaili, N. A., \& Palil, M. R. (2017). Crowdfunding: A Collaborative Waqf Based Internet Platform. Kuala Lumpur International Islamic Studies and Civilisations Conference: Al Maqasid As-Syariah as the Guiding Principles of the Past, Present and Future Life.

Thaker, M. M., Thaker, H. M., \& Pitchay, A. A. (2018). Modeling Crowdfunders' behavioral Intention to adopt the crowdfunding-waqf model (CWM) in Malaysia. International Journal of Islamic and Middle Eastern Finance and Management, 231-249.

Ubed, A. (2014). Analisis Hasil dan Metode Fundraising Wakaf Uang Badan Wakaf Indonesia (BWI). Jurnal Bimas Islam, 605-632.

Worth, M. J. (2017). Nonprofit Management: Principles and Practice. Nonprofit and Voluntary Sector Quarterly. 511 